\title{
Chronic Advanced Pulmonary Hypertension
}

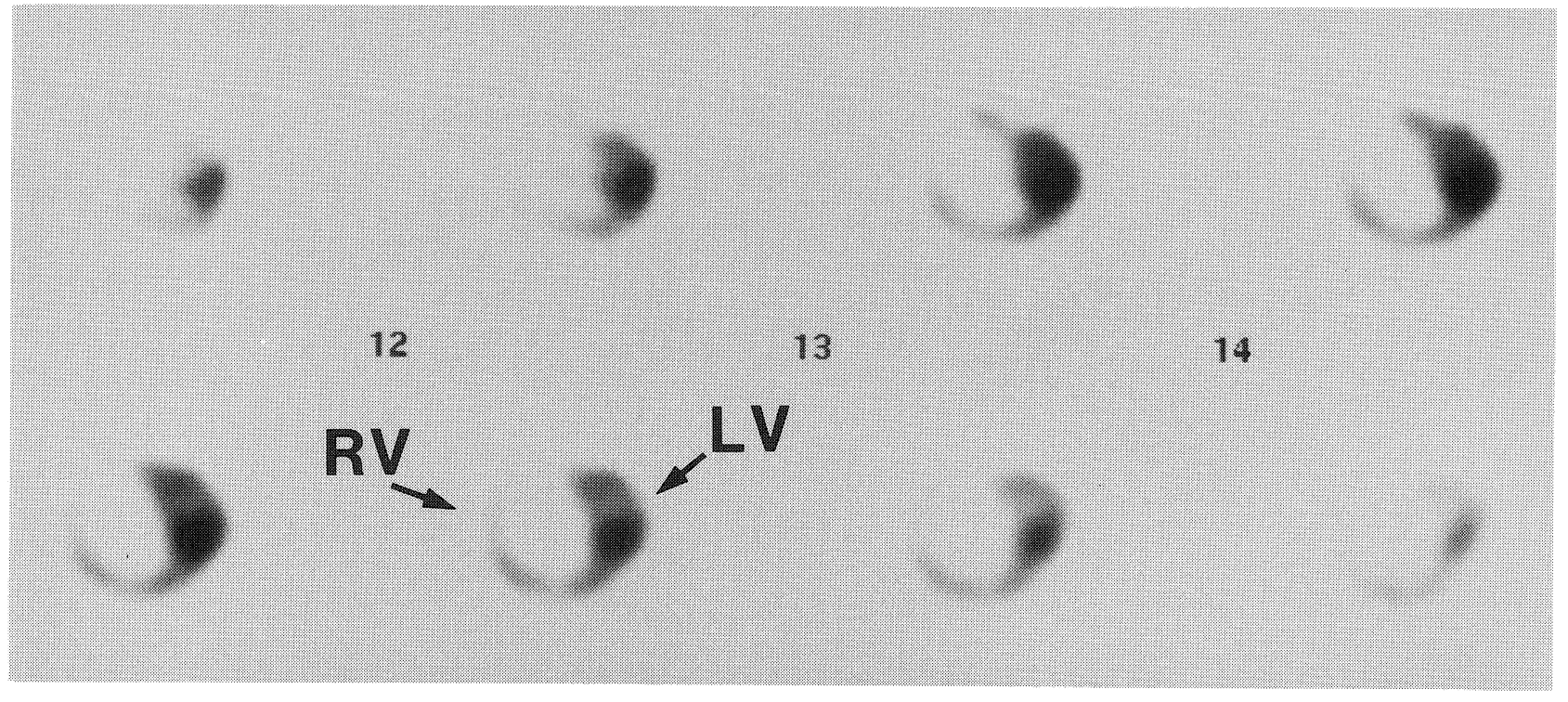

Figure. A short-axis view on thallium-201 myocardial scintigraphy demonstrated marked dilatation and hypertrophy in the right ventricle $(R V)$ with a relatively small and compressed left ventricle (LV).

A 74-year-old woman with an eleven-year history of chronic pulmonary thromboembolism was admitted because of precordial oppression on exertion. An electrocardiogram showed a decreased R-wave amplitude in the anterior precordial leads, necessitating differentiation from ischemic heart disease. A short-axis view on thallium-201 myocardial scintigraphy demonstrated a characteristic 'diamond ring'-shaped image, depicting marked dilatation and hypertrophy in the right ventricle (RV) with a relatively small and compressed left ventricle (LV). Although myocardial ischemia was difficult to evaluate, intensive anticoagulation therapy resulted in symptomatic improvement, and the patient was discharged. We consider the present case to be the end-stage of long-term RV overloading.

Key words: pulmonary thromboembolism, thallium-201 myocardial scintigraphy

Norifumi Takeda, MD, Kouichi Kitahara, MD and Tetsuya SumiYoshi, MD Department of Cardiology, The Sakakibara Heart Institute Received for publication April 3, 2002; Accepted for publication April 17, 2002 Reprint requests should be addressed to Dr. Norifumi Takeda, Department of Cardiology, The Sakakibara Heart Institute, 